
\title{
25 Research Soure \\ Identification Of Locking Segment In A High-Locality Landslide In Shidaguan, Southwest China
}

\section{Yuntao Zhou ( $\nabla$ zzyytt2040@tom.com )}

Southwest Jiaotong University

Xiaoyan Zhao

Southwest Jiaotong University

Jiajia Zhang

Chinese Academy of Geological Sciences Institute of Exploration Technology

Minghui Meng

Sichuan Huadi Construction Engineering Co. Ltd.

\section{Research Article}

Keywords: High-locality landslide, geomorphological identification, spatial-temporal deformation identification, Rock bridge, Locking segment

Posted Date: August 5th, 2021

DOI: https://doi.org/10.21203/rs.3.rs-766936/v1

License: (1) (1) This work is licensed under a Creative Commons Attribution 4.0 International License. Read Full License

Version of Record: A version of this preprint was published at Natural Hazards on January 14th, 2022. See the published version at https://doi.org/10.1007/s11069-021-05162-1. 


\section{Abstract}

Identification of the locking segments is crucial for assessing the potential runout risk and the overall stability of the high-locality landslide. However, during the field investigation, it is difficult to identify the locking segments before landslide failure due to their concealment. Tizicao landslide, a high-locality landslide, is used as the field example for the locking segments identification analysis in this study. Based on the geomorphology and spatial-temporal deformation in the landslide, the identification characteristics of the locking segments of the landslide are analyzed macroscopically, and the location and area of the locking segments are determined based on the analysis results. The field investigation methods are used to verify the identification results, including the monitoring of surface and deep displacement, geological borehole drilling, and oblique photography using drones. The results show that the locking segment of the Tizicao landslide lies at the southern slope toe, which covers an area of about $4.69 \times 10^{4} \mathrm{~m}^{2}$, accounting for $15.2 \%$ of the total area of the landslide. The significant different developmental characteristics are observed in respect of the surface displacement, deep displacement, surface crack, and sliding zone soil between locking and non-locking segments. It is concluded that the formation and evolution of the locking rock masses in the Tizicao landslide are closely related to the development of local folds and S-shaped river valleys, differential unloading due to river cutting, and earthquake-induced damage to rock masses in the landslide area.

\section{Introduction}

Locking segments, also called rock bridges (Einstein et al. 1983; Frayssines and Hantz 2006) or locked sections (Huang 2012; Chen et al. 2018) in the rockslides, play a critical role in the occurrence of a highlocality landslide, and the overall stability of the landslides involved depends on the strength and deformation of the locking segments (Jennings 1970; Jaeger 1971; Pariseau et al. 2008; Chen et al. 2018). A high-locality landslide with locking segments usually possesses huge potential energy. When the locking segments of the landslide detached from the parent rocks, the fragmental materials formed by the landslide tend to cause a high-speed, remote-distance, and integrated geological disaster chain, with a development process of "rockfalls $\rightarrow$ rockslides $\rightarrow$ debris flows", usually resulting in catastrophic effects and severe casualties. The high-locality landslides with locking segments have been investigated in the previous studies. For example, on June 5, 2009, a huge catastrophic rockslide with a rock mass barrier in the front took place at the crest of the Jiweishan Mountain in Wulong County, Chongqing, China, with a long runout distance of $1,500 \mathrm{~m}$, and the landslide body about $7.0 \times 10^{6} \mathrm{~m}^{3}$ was moved towards the valley; as a result, about $0.47 \mathrm{~km}^{2}$ of the residential area was buried, an iron ore mine was destroyed and 74 people were killed (Xu et al. 2010; Yin et al. 2011). On August 27, 2014, a similar large-scale landslide with one locking segment at its front toe occurred in Fuquan County, Guizhou province, China, which killed 23 people and destroyed 77 houses (Lin et al. 2018). On June 24, 2017, a catastrophic landslide with locking masses in the front was triggered above the Xinmo Village, Maoxian County, Sichuan Province, China; it buried the whole Xinmo village (10 deaths, 73 people missing) and the sliding mass blocked over a distance of 1,300 m of the Songping River (Kang et al. 2019; Wang et al. 2019a). 
Therefore, the landslide with locking segments possesses a huge threat to people's lives and properties, to reduce the risk of landslides with locking segments, it is essential to identify the location, geometry, and area of the locking segments before the landslide failure.

The landslide with locking masses usually shows some identification characteristics. For example, a nearly horizontal Cretaceous stratum with a thickness of $350 \mathrm{~m}$ is observed in the anti-sliding section in the front of the Vajont landslide (Broili 1967). Moreover, the fresh rock mass surface is observed in the locking section in the front of the failed slope of the Jiweishan collapse reported by Yin et al. (2011). The Dongmiaojia landslide close to the Xiaolangdi Hydropower Station on the Yellow River, China, is a typical bedding rocky landslide, and the accumulation body in the front is the anti-sliding section of the whole landslide, on which great numbers of bulging-induced cracks and compressive cracks have developed (Xu et al. 2014). Xiaoba landslide took place in Guizhou Province, China, whose front is a locking section of dolomite, and the obvious stress concentration and plastic deformation on the locking masses in the front of the landslide were found by Lin et al. (2018). Based on the spatial-temporal deformation characteristics of the Xinmo landslide, Kang et al. (2019) found the bulge reduction of the sliding surface and inferred that the locking masses should lie in the front of the landslide. Two landslides happened on the right bank of the Jinsha River in Baige Village, China, blocking the river; as discovered in field surveys, shear surfaces were distinctly visible in the anti-sliding areas in the front of the Baige landslide (Deng et al. 2019). By studying the landslides' deformation characteristics, damage patterns, and fresh sections of rock mass analysis, the parameters of locking segments such as the position and area, can be obtained to a certain extent after landslides failure. However, it is not easy to acquire accurate information on locking segments prior to landslides due to their concealment. And the identification characteristics of locking segments are yet to be analyzed in a systemic and refined manner, despite the identification characteristics of locking segments can be observed from multiple disastrous landslides.

In this study, the Tizicao landslide, a large-scale and high-locality landslide that occurred from 2013 to 2017 , is used as an example to analyze the identification of the locking segments. The identification characteristics of the locking segments in the Tizicao landslide are analyzed based on geomorphology and spatial-temporal deformation. Field survey methods, including the monitoring of surface and deep displacement, geological borehole drilling, and oblique photography using drones, were used to verify the validity of the identification results. Additionally, the evolutionary process of the locking masses in the landslide is further discussed according to the field surveys results.

\section{Geological Setting}

The Tizicao landslide is located in Maoxian County, Sichuan Province, Southwest China (Fig. 1), with geographical coordinates of $31^{\circ} 53^{\prime} 14.89^{\prime \prime} \mathrm{N}$ and $103^{\circ} 40^{\prime} 51.12^{\prime \prime} \mathrm{E}$. It lies on the right bank of the valley of Minjiang River and faces the Shidaguan Town on the left bank of the river, with National Highway G213 passing by its foot. 
The Tizicao landslide is located in the lower part of the right bank slope of the Minjiang River. Its rear and toe are at an elevation of $2415 \mathrm{~m}$ and $1950 \mathrm{~m}$ (Fig. 2a), respectively, and thus the relative elevation difference reaches $465 \mathrm{~m}$. The relative elevation difference between the toe of the landslide and the lower riverside of the Minjiang River is $220 \mathrm{~m}$. The Tizicao landslide is therefore determined as a high-locality landslide.

The Tizicao landslide is approximately $680 \mathrm{~m}$ long and $570 \mathrm{~m}$ wide (Fig. 2b), with an average thickness of approximately $45.1 \mathrm{~m}$ and a volume of $1388.2 \times 10^{4} \mathrm{~m}^{3}$. On July 3,2017 , a local collapse occurred in the front of the landslide body in the north, with a volume of approximately $6.0 \times 10^{4} \mathrm{~m}^{3}$, and it blocked the Minjiang River for several hours. Fortunately, there were no casualties. In case of large-scale sliding, this landslide will directly threaten the lives of 30 people on the slope body, even seriously threaten the lives of 113 people in the Shidaguan Town below the landslide, and will directly strike more than 30 buildings and the National Highway G213 at a distance of 2 kilometers. Meanwhile, the Minjiang River may be blocked to form barrier lakes and induce secondary floods, which will endanger the towns, villages, and infrastructures along the Minjiang River and directly threaten the properties of about RMB 86 million. Nonetheless, the landslide gradually became stable by the end of 2017 after multiple deformations and partial collapses in $2013-2017$, owing to the anti-sliding of local locking segments in its front.

The site area is in the shape of a round-backed armchair (Fig. 2), high in the west and low in the east. The aspect and mean gradient of the failed slope are $44^{\circ}-78^{\circ}$ and $30^{\circ}-40^{\circ}$, respectively, with a shape of steps vertically. The lower riverside of the Minjiang River to the upper section at an elevation of $1900-2000 \mathrm{~m}$ is a straight steep slope with a slope of about $70^{\circ}$, where bedrocks are mostly exposed. The failed slope is mainly distributed in the section at an elevation of $2000 \mathrm{~m}$ to the rear of the landslide, with a mean slope of about $25^{\circ}$. The alternate steep and gentle steps, and the development of free-face conditions provide favorable topographic conditions for the development of the Tizicao landslide.

The average monthly rainfall is about $134.7 \mathrm{~mm}(2012-2018)$, with a peak value of $400 \mathrm{~mm}$. The rainfall mainly concentrates from June to October, accounting for $85 \%$ of the annual rainfall. As shown in Fig. 3a, the historical monthly rainfall and deformation data of the landslide show that the deformation mainly occurred from June to September, especially the deformation quickly developed in September. The daily rainfall statistics and the curve of typical surface displacement monitored from June 1 to October 30 in 2017 are shown in Fig. 3b. The violent landslides occurred after 20 days of heavy rain and 10 days of short-term rain, with the maximum displacement reaching $1210 \mathrm{~mm}$. It can be concluded that the landslides lag behind rain.

The Tizicao landslide mainly consists of thin silty clay on the surface and broken phyllite $\left(Q_{4}{ }^{\text {del }}\right)$ below, while the sliding bed mainly comprises the carbonaceous phyllite of the Devonian Weiguan Group $\left(D w g^{2}\right)$. The phyllite is greyish-black and greyish-yellow and is interbedded with a small number of quartz veins locally. The phyllite layers show an attitude of $197^{\circ} \angle 71^{\circ}$. The carbonaceous phyllite is weak and 
broken, indicating that it has poor physical and mechanical properties, with a potential risk of collapse, slide, and deformation during the rainy season.

The massive amount of developed broken carbonaceous phyllite in the slope body is closely related to active structures. Shidaguan Town lies in the middle part of the NS-trending seismic belt, where intensive earthquakes in history developed. Since the beginning of the 20th century, it successively experienced the Diexi earthquake in 1933 (Ms 7.5), the Songpan-Pingwu earthquake in 1976 (Ms 7.2), the Wenchuan earthquake in 2008 (Mw 7.9), and the Jiuzhaigou earthquake on August 8, 2017 (Ms 7.0; Fig. 4). Among them, the Diexi earthquake, with a hypocenter depth of $6.1 \mathrm{~km}$ and an epicenter of merely $1.3 \mathrm{~km}$ away from the landslide center, caused a variety of disasters, such as massive rockfalls, landslides and debris flows, and devastated the former Diexi Town (Wang et al. 2019a). The Diexi earthquake shattered numerous mountains due to its epicentral intensity up to 10 degrees, thus resulting in broken rock masses on the slope surface. In addition, a great number of secondary folds (Fig. 5a) develop in the bedrock of the site area and clear corrugations are visible on the steep wall below the front landslide toe, and fractured rock masses, secondary folds, hollow structures, and argillaceous fillings (Fig. 5b) can also be observed at the slope foot. Many holes or empty spaces reserved in the fractured rock masses after earthquakes, formed the hollow structures, some of which were filled with argillaceous materials. Therefore, earthquakes and tectonic movements are the critical factors causing broken phyllite masses in the landslide body.

\section{Methods}

The identification method is divided into two steps. The first step is to obtain the location and area of the locking segment of the landslide by the method of combining geomorphology analysis with spatialtemporal deformation analysis of the landslide. The second step is to verify the validity of the identification results by using field investigation methods such as the monitoring of surface and deep displacement, geologic borehole drilling, and oblique photographic using drones.

A special S-shaped river landform is developed below the Tizicao landslide, which is a concave bank under the north side of the slope and a convex bank beneath the south side. From a geomorphological point of view, landslides rarely occur on the convex banks, but more frequently on concave banks (Lulseged and Hiromitsu 2004). From the topographical point of view, the convex slope is more stable than the concave slope under the same conditions (Cała 2007). To the Tizicao landslide, the convex bank below this landslide will act as a barrier area for the entire slide, and the concave bank beneath will facilitate the occurrence of the slide. Then the sliding body on the convex bank will form a potential locking mass because it can resist the sliding of the landslide. Based on this, the orthoimages, topography, geology, hydrogeology, and site surveys involved were collected based on available literature. A post-failure orthoimage (Fig. 2a) was obtained by applying oblique photography techniques with drones. A set of 131 photos (resolution of $3840 \times 2160$ pixels) were processed using the software Pix4Dmapper, and the high-resolution photos were selected for visual inspection. 
As the low amount of deformation and the small number of signs of deformations in the landslide body are symbols of the resistance area of landslides (Deng et al. 2019), these characteristics can also be used to identify the locking segment. Hence, we have recorded the temporal-spatial deformations. The time series were recorded in Fig. 3a, while the deformation location, crack development and other characteristics of each landslide event were documented in Figs. 6-8.

To verify the validity of identification results of the locking segment, we used traditional field survey methods, including the monitoring of surface and deep displacement, geologic borehole drilling, and oblique photographic using drones. These methods not only can obtain the location and area of the locking segment but also the depth parameters, as well as the developmental differences of locking segment and non-locking segment.

Firstly, a topographic plan (Fig. 6) was obtained through mapping. Twenty boreholes were deployed in the landslide body to explore the geological structure of the landslide, the integrity of rock masses, and the depth of the sliding surface. This work was supported by Sichuan Huadi Construction Engineering Co., Ltd. (2018). The locations and depth of the boreholes are shown in Fig. 6 and Table 1, respectively. Four geological profiles were obtained based on these borehole data, which are sequentially numbered A-A', B$B^{\prime}, C_{-} C^{\prime}$, and D-D' (Fig. 7). Additionally, four exploratory wells (Fig. 6) were deployed in the landslide body to further explore the integrity of the rock masses. Then, as shown in Fig. 8, twenty-four fixed non-prism monitoring points ( $\mathrm{T} 1$ - T24) were deployed in the landslide body to mainly monitor the surface displacement from June 1, 2017, to October 2, 2017, and they almost covered the entire landslide body. These raw data of the surface displacement were processed using the measurement adjustment software DDM to obtain their deformation amount and deformation rate.

Among the twenty boreholes, seven boreholes (D01 - D07, Fig. 8) were selected to monitor the deep displacement of the landslide. They were deployed along the profiles A-A', C-C', and D-D', including two along the profile A-A' (Nos.: D01, D02), three along profile C-C' (Nos.: D03, D04, D05), and two along profile D-D' (Nos.: D06, D07).

Table 1

Depth of the twenty boreholes

\begin{tabular}{|lcccccccccc|}
\hline Borehole No. & zk01 & zk02 & zk03 & zk04 & zk05 & zk06 & zk07 & zk08 & zk09 & zk10 \\
\hline Depth / m & 41.5 & 48.1 & 54.3 & 52.4 & 69.0 & 35.6 & 36.4 & 28.5 & 43.1 & 56.8 \\
\hline Borehole No. & zk11 & zk12 & zk13 & zk14 & zk15 & zk16 & zk17 & zk18 & zk19 & zk20 \\
\hline Depth / m & 34.1 & 58.2 & 66.1 & 50.0 & 68.8 & 66.6 & 46.2 & 54.5 & 75.0 & 75.5 \\
\hline
\end{tabular}

To find out the deformation characteristics of the landslide, eleven major surface cracks and bulginginduced cracks were drawn in the topographic plan (Fig. 8), and the cracks were photographed with high definition digital camera (resolution of $3264 \times 2488$ pixels), as shown in Fig. 9 .

\section{Results}




\subsection{Identifications of locking segments \\ 4.1.1 Geomorphological identification}

As shown in Figs. 2a and 2c, a typical S-shaped valley landform develops under the Tizicao landslide, with concave and convex bank parts gradually forming on the valley's both banks subject to river cutting. Under the northern side of the Tizicao landslide lies a concave bank part, where the slope foot is about $220 \mathrm{~m}$ higher than the water level of the Minjiang River and the average slope is about $65^{\circ}$. The broken phyllite (Fig. 2e) is observed on the slope surface in this part because of the strong cutting of the Minjiang River. A convex bank part is located under the southern side of the Tizicao landslide, with a gentle slope of about $35^{\circ}$. Besides, vegetation is evenly distributed and relatively intact phyllite (Fig. $2 \mathrm{~d}$ ) is exposed on the slope surface. The concave and convex bank parts of the S-shaped valley under the Tizicao landslide are greatly different in slope and lithology. The concave bank part is characterized by a relatively steep slope and broken rock masses, while the convex bank part has a gentle slope and intact rock masses. Therefore, the rock masses at the southern side of the landslide above the convex bank part reserve their integrity and constitute the potential locking segment of the landslide (Figs. $2 a-b)$.

\subsubsection{Identification of spatial-temporal deformations}

According to the deformation time series (Fig. 3a), the middle-front part of the Tizicao landslide began to deform in 2013, while the houses on the slope body started to crack and dislocate downwards. In September 2014, the middle part of the landslide front gradually collapsed. As a result, a chute with a width of about $60 \mathrm{~m}$ and a height of $200 \mathrm{~m}$ (Figs. 2a and 9f) was formed at the northern side of the landslide and the accumulated body fell into the Minjiang River to form a landslide dam. At the same time, the rear of the landslide began to crack. From August to September in 2015, the landslide deformed more obviously and severely, resulting in additional wider, longer cracks. After continuous deformation during the rainy season in 2016 and 2017, the rear and front of the northern landslide dislocated downwards for up to more than $10 \mathrm{~m}$ locally by July 2017 (Figs. 9e and 9f), leading to continual collapse and rockfall near the front toe. Since October 2017, the deformation of the landslide has slowed down and tended to stabilize (Fig. 3b).

The deformation history of the Tizicao landslide shows that the landslide body has undergone intensive sliding on the northern side, with a sliding distance of more than $10 \mathrm{~m}$. A distinct steep wall at the rear of the landslide's northern side is observed (Fig. 9e), and the collapse occurred in the front of the landslide, with a volume of about $6 \times 10^{4} \mathrm{~m}^{3}$. As indicated by the expansion and penetration of the cracks, the rear of the landslide is completely penetrated by cracks L07 and L08 (Fig. 8). The crack L11 (Fig. 8) on the northern part of the landslide body penetrate the landslide from the rear to the slope foot. However, the crack L08 (Fig. 8) only penetrates 1/3 of the landslide's southern side. The Tizicao landslide tends to deform northeastwards and there is no distinct deformation in the front of the landslide's southern side. Therefore, the rock masses in the front of the landslide's southern side serve as potential locking masses of the Tizicao landslide. 
Based on the identification analysis of geomorphology and spatial-temporal deformations of the Tizicao landslide, it can be concluded that the locking segment of the landslide lies at the south toe of the slope (Figs. 2a-b; Figs. 7c-d), which covers an area of about $4.69 \times 10^{4} \mathrm{~m}^{2}$, accounting for $15.2 \%$ of the total landslide area.

\subsection{Verification of identification 4.2.1 Surface deformation}

The isoline map of the surface displacement (Fig. 10) was plotted with the data acquired from the 24 monitoring points (Fig. 8). As shown in Fig. 10, the Tizicao landslide slid toward north by east in general from June 1, 2017, to October 2, 2017. The maximum surface displacement (1210 mm) occurred at the northern toe, which is consistent with the location where the front collapsed (Fig. 2b). The rear and the middle parts shared relatively similar surface displacement that ranges from $150 \mathrm{~mm}$ to $300 \mathrm{~mm}$, indicating that the rear and the middle parts slid as a whole. The southern area of the slope toe features the minimum surface displacement throughout the whole landslide, with displacement ranges between $30 \mathrm{~mm}$ and $150 \mathrm{~mm}$, which therefore serves as the anti-sliding area of the entire landslide. Hence, the area of the minimum surface displacement is following the locking area of this landslide.

\subsubsection{Deep displacement}

The curves of the monitored cumulative deep displacement are shown in Fig. 11. The significant deep displacement is found at boreholes D01, D02, D03, and D04, with a trend of increase firstly and then decrease with an increase of depth. The order of the maximum displacement $S_{\max }$ is: $S_{\max }(D 01)>S_{\max }$ (D04) $>S_{\max }(D 02)>S_{\max }$ (D03), and the corresponding depth of the $S_{\max }$ is consistent with the depth of the sliding surface. The maximum deep displacement $(5 \mathrm{~mm})$ was acquired at a depth of $45 \mathrm{~m}$ at D01. The monitoring borehole D01 was deployed behind the front collapse area of the landslide, where the maximum surface displacement was obtained. The results indicated the consistency between the deep displacement and the slope surface displacement.

No displacement was monitored at boreholes D05, D06, and D07, as shown in Fig. 11. Based on the monitored surface displacement, as shown in Fig. 10, deep rock masses produced no displacement but the slope surface was subject to deformation to some extent at the positions of D05, D06, and D07. As shown in Figs. 6 and 8, D05 is adjacent to the locking segment, and D06, D07, and the locking segment are all located in the profile $D-D$ '. The locking masses in the front can well prevent the rear and adjacent slope bodies from sliding.

\subsubsection{Surface cracks}

Surface crack is an important phenomenon associated with the formation and development of landslides (Wang et al. 2020). Based on the crack investigation, the mechanical properties and development trends of landslides, such as the distribution scope, mechanical mechanisms, and developmental stages of landslides, as well as the thickness of the sliding masses, can be assessed and predicted objectively. 
According to the field survey results of the Tizicao landslide, as shown in Fig. 8, the landslide shows conspicuous deformation characteristics, including tension cracks at the rear (L06, L07, and L08), gradual tension cracks, and depression in the middle part (L03, L04, and L05), pinnate shear cracks on the northern side of the middle part (L11), and compressive cracks (L09 and L10; Figs. 9b and 9c), bulging-induced disintegration (Fig. 9d), and slumping-induced deformation (L01 and L02) in the front.

The development and distribution map of the cracks is shown in Fig. 8, and numerous tension cracks and shear cracks mainly developed at the rear, in the middle part, and on the north side of the front in the landslide, while bulging-induced cracks and a small number of compressive cracks primarily occurred in the middle and southern parts of the front. Although it is very common for bulging-induced cracks and compressive cracks to develop in the front of thrust-induced landslides, the properties of the rock masses bearing these two kinds of cracks differ obviously. As shown in Fig. 12, compressive cracks are formed in the rock masses with locking masses in front under the push of landslides. For intact rock masses, only a small number of compressive cracks (e.g. compressive cracks $\mathrm{C} 1$ and $\mathrm{C} 2$ ) are produced due to the high strength of the rock masses. As the push of landslides increases, they gradually expand in the push direction until they completely penetrate the rock masses. In contrast, for broken rock masses, large numbers of compressive cracks are formed along the push direction of landslides due to their low strength. These rock masses suffer large compressive deformation, leading to a gradual expansion of original cracks along two directions vertical to the push direction of landslides. This is an important reason why numerous bulging-induced cracks were formed inside the landslide body. The two cases are shown in Figs. 12a and 12b, respectively and they can produce different effects on landslides. For the former, cracks in rock masses gradually expand as the push of the landslide increases. In this case, slope failures can only occur laterally along $\mathrm{C} 1$ or $\mathrm{C} 2$. In comparison, for the latter, sliding masses will cause general damage along the newly produced crack $\mathrm{C} 3$ as the bulging-induced cracks extend, expand, and penetrate in the directions vertical to the push direction of landslides.

As shown in Fig. 2, the rock masses with a width of about $50 \mathrm{~m}$ in front of the bulging-induced cracks (Fig. 9d) are locking masses. However, the rock masses bearing bulging-induced cracks are not locking masses since they have been completely crushed. In contrast, the rock masses containing compressive cracks (Figs. 9b and 9c) and the rock masses in front of the compressive cracks are all locking masses. They are about $300 \mathrm{~m}$ wide and the width of the locking segment increases from the middle part to the southern side in the front of the slope. The bulging-induced cracks and compressive cracks, especially a single compressive crack, serve as important indicators in identifying and positioning locking masses of landslides and determining the geometric morphology of the locking masses.

\subsubsection{Borehole cores}

The Tizicao landslide body mainly consists of the heavily weathered mass on the surface and fractured rock masses below. Among them, the fractured rock masses were distributed throughout the landslide, with a thickness varies from $10 \mathrm{~m}$ to $50 \mathrm{~m}$. The protoliths are greyish-black and black carbonaceous phyllite. The sliding zone soil is $1.2-3.0 \mathrm{~m}$ thick and has a dense structure, which is mainly gray or tawny and consists of silty clay interbedded with breccia and broken stones (Fig. 13a). The silty clay mainly 
appears to be hard plastic, dampish-humid, and dense (Fig. 13b). The breccia and broken stones mainly consist of phyllite. They are angular and subangular in shape, with a diameter of $2-20 \mathrm{~mm}$ mostly. The rock masses of the sliding bed are generally less weathered compared with the fractured rock masses in the landslide body and consist of moderately-weakly weathered rock masses. Its borehole cores are generally intact and in the shape of long columns (Fig. 13a).

The cores of boreholes zk15, zk19, and zk20 (Fig. 13d) are more intact compared with other borehole cores, which are consistent with the relatively intact phyllite revealed by TJ04 (Fig. 13c). They are moderately-weakly weathered, which is roughly the same as the rock masses of the sliding bed. In contrast, other borehole cores are more fractured (e.g., rock masses above the sliding zone in Fig. 13a) and strongly weathered. In addition, sliding zone soil with the mirror surface and scratch (Fig. 13b) can be observed in these borehole cores, while there is no sliding zone soil in the cores of zk15, zk19, and zk20. It is concluded that rock masses at the positions of $\mathrm{zk} 15, \mathrm{zk} 19$, and $\mathrm{zk} 20$ are stable and have not slid, and there are locking masses at these positions.

The distribution of the rock quality designation (RQD) values of all borehole cores is plotted as shown in Fig. 15. It can be seen from this figure that RQD values of borehole cores in profiles $A-A^{\prime}(z k 01, z k 02, z k 03$, $\mathrm{zk04}$, and zk05) and $\mathrm{B}^{-B^{\prime}}(\mathrm{zk06}, \mathrm{zk07}, \mathrm{zk08}, \mathrm{zk09}$, and zk10) are all less than $20 \%$, while the RQD values of borehole cores in profiles C-C' (zk11, zk12, zk13, zk14, and zk15) and D-D' (zk16, zk17, zk18, zk19, and $z k 20)$ are between $25 \%$ and $80 \%$. According to the criterion of the strength and deformability of jointed rock mass (Hoek and Bray 1981), the rock masses of the borehole cores in profiles A-A' and B-B' are very poorly jointed ones (broken) and the rock masses of the borehole cores in profiles C-C' and D-D' are poorly-heavily jointed (intact). The RQD values of zk15, zk19, and zk20 that lie in the middle part and on the southern side of the landslide front (Figs. 6 and 14) are greater than $68 \%$. Therefore, the rock masses revealed by these boreholes are relatively intact, which coincides with the position of the locking segment (Fig. 2b).

\section{Discussion}

The evolutionary process of the locking segment in the Tizicao landslide is explored from the aspects of tectonic movement (development of local folds), river evolution (development of S-shaped river valleys, and differential unloading duo to river cutting), and earthquakes (earthquake-induced damage to rock masses) according to field surveys and previous research results.

\section{(1)Developmental stage of local folds}

The Tizicao landslide site lies in the middle part of an NS-trending seismic belt (Fig. 4), where historic intensive tectonic movements have developed. According to research on regional structures in the Minjiang River basin, the carbonaceous phyllite in the landslide body was formed in the Devonian and developed in 410 - 354 Ma B.P. (Xie et al. 2020). The rise of the Minshan Uplift Zone is an important morphotectonic event on the eastern margin of Qinghai-Tibet Plateau in the Late Neogene, and it mainly developed during 6 - 3 Ma B.P. in the Pliocene (Arne et al. 1997; Kirby et al. 2002). The anti-dip strata 
(Fig. 7) in the landslide area were formed and folds were formed locally in the strata (Fig. 5a). The Minjiang River began to downcut at an average rate of $770 \mathrm{~m} / \mathrm{Ma}$ in the Neogene, reaching a depth of more than $2000 \mathrm{~m}$, and then it further downcut in the Middle and Late Pleistocene (since 0.8 Ma; Zhang et al. 2005), slightly later than the rise of the Minshan Uplift Zone. Therefore, the local folds in the lower part of the landslide were formed before the river valley downcut. Local folds resulted in fractured rock masses, which were favorable for the formation of the S-shaped river valley of the Minjiang River in the landslide area.

\section{(2)Developmental stage of S-shaped river valley}

Rivers generally develop along a straight line and bend mainly due to different terrain and stratum lithology. For the Minjiang River, when it downcut to local folds (Fig. 5a) in the Tizicao landslide, the fractured rock masses in the local folds were washed away subject to water erosion and attenuation, consequently, the river initially bent. Water flows the most quickly and possesses the highest hydrodynamic force along the centerline of a river (Ferguson et al. 2003). After the Minjiang River bent, the water flowing along the river centerline struck the bank right ahead. The increased water pressure in concave bank portions leads to the formation of the spiral circular water flow (Schnauder 2012). Besides, the concave bank portions are further denuded, and the denuded sand and stones are accumulated on convex bank portions. Finally, a concave bank part and a convex bank part (Figs. 2a and 2c) were formed under the front slope on the northern and southern sides of the site, respectively.

\section{(3) Differential unloading stage due to river cutting}

The unloading of the rock masses on a slope occurs throughout the formation of a river (Ghirotti et al. 2011). When a free face is formed by a river cutting rock layer, the rock masses lose lateral support and then begin to unload. The rock masses decrease in strength as joints and fissures develop, and unloading zones with a certain depth gradually form within the slope (Mitchell et al. 2009). However, the unloading of rock masses differs significantly between the concave and the convex banks (Keshavarzi et al. 2010). Concave bank parts are subject to high hydrodynamic pressure and thus the rock masses in the slope of these regions are gradually denuded and washed away by water. The integrity of the rock masses is further destroyed and the slope is gradually becoming steep. The stress concentration at the slope foot of concave bank parts, further damages and disintegrates the rock masses while deepening the unloading zones (Feda 1977). The convex bank suffers small hydrodynamic pressure and massive sand and stones gradually accumulate at the bank slope foot. Consequently, the rock masses at the slope foot are protected by overlying sand and stones and are gradually free from water flow. Besides, the slope at the foot of convex bank parts gradually becomes gentle owing to the accumulation of sand and stones. The stress concentration at the slope foot gradually vanishes. The gentle slope of the convex bank parts slows down the development of the unloading zones and reduces their depth to some extent. Accordingly, the rock masses in the slope remain relatively intact and the locking segment is formed above the slope of the convex bank part, while the collapse area is formed above the slope of the concave bank part.

(4) Damage stage of rock masses induced by earthquakes 
Since the beginning of the 20th century, the Tizicao landslide has suffered multiple violent earthquakes. Among them, the Diexi earthquake in 1933 with an epicenter of $1.3 \mathrm{~km}$ away from the landslide center particularly caused fractured rock masses on the slope surface.

As indicated by existing literature, the unloading zones formed from river cutting are $10-30 \mathrm{~m}$ deep while the structure and integrity of the rock masses remain to a certain degree (Sun et al. 2012). This is in disagreement with the rock masses in the Tizicao landslide, of which the depth of the unloading zone is $40-50 \mathrm{~m}$ (i.e., the depth of the sliding surface) and most of the rock masses are broken (Fig. 14). Meanwhile, there are numerous hollow structures in the rock masses (Fig. 5b). These phenomena are closely related to earthquakes.

When seismic waves are transmitted to the site, the rock masses in the area were broken up due to earthquake shaking, leaving the loose structure and lower integrity of the rock masses (Massey et al. 2016). In addition, since the acceleration on a slope surface increases with the slope gradient (Wang et al. 2019b), the seismic tensile stress on the slope surface causes more severe damage to rock masses. The steeper the slopes, the more significant increment in acceleration (Yasuda et al. 2016; Wang et al. 2019b). Compared to the convex bank part under the Tizicao landslide, the concave bank part under the landslide has a higher slope gradient, more broken rock masses, and a deeper unloading zone. In contrast, the rock masses in the convex bank part remain relatively intact and form the current locking masses.

\section{Conclusions}

In order to identify the locking segments of Tizicao landslide, the geomorphological identification and the spatial-temporal deformation identification are used to analyze the location and area of the locking segments. The identification results are verified through field investigation methods, including the monitoring of surface and deep displacement, geological borehole drilling, and oblique photography using drones. The different developmental characteristics of the surface displacement, deep displacement, surface cracks, and sliding zone soil between locking and non-locking segments are analyzed based on the field investigation results. Besides, the evolutionary process of the locking segment in the Tizicao landslide is analyzed from the aspects of tectonic movement, river evolution, and earthquakes. The following conclusions can be drawn:

(1)The convex bank part of the S-shaped valley provides geomorphological conditions for the formation of the locking segment in the landslide. It is one of the identification characteristics of the locking segment in terms of geomorphology. The area with fewer indications of deformation in the landslide body is another identification characteristic of the locking segment in the Tizicao landslide.

(2)The locking segment of the Tizicao landslide lies at the southern slope toe based on the identification analysis results. It covers an area of about $4.69 \times 10^{4} \mathrm{~m}^{2}$, accounting for $15.2 \%$ of the total area of the landslide. 
(3)The surface displacement in the locking segment is the minimum throughout the whole landslide; it is much less than the surface displacement in the non-locking segment. The deep displacement in the locking segment is zero on the sliding surface, indicating that the deep rock masses in the locking segment have not slid. A single compressive crack develops in the locking segment, and bulging-induced cracks usually develop at the rear of the locking segment. The bulging-induced cracks and compressive cracks (especially a single compressive crack) serve as essential indicators in identifying and positioning locking masses and determining the geometrical morphology of the locking masses. No sliding zone soil develops in borehole cores of the locking segment, while scratches and mirror surfaces of sliding zone soil can be observed in borehole cores of non-locking segments. In the locking segment, rock masses remain relatively intact and the RQD values of the borehole cores are much higher compared to nonlocking segments.

(4)The locking masses in the Tizicao landslide have evolved in four stages, namely the developmental stage of local folds, the developmental stage of the S-shaped river valley, differential unloading stage due to river cutting, and the damage stage of rock masses induced by earthquakes. The local folds resulted in fractured rock masses, which were favorable for the formation of S-shaped river valley of Minjiang River in the landslide area. Then the fractured rock masses in the local folds were washed away and a greatly curved S-shaped river valley was formed. Differential unloading due to river cutting caused the rock masses in the concave bank part of the Minjiang River to further break, while the rock masses in the convex bank part remained intact. Owing to the significant increase in acceleration with slope gradient, earthquakes induced much more damage to the rock masses in the concave bank part due to its higher slope gradient, but caused less damage to the rock masses in the convex bank part because of the lower slope gradient. The rock masses in the convex bank part remain relatively intact and serve as current locking masses.

\section{Declarations}

\section{Declaration of competing interest}

The authors declare that they have no known competing financial interests or personal relationships that could have appeared to influence the work reported in this paper.

\section{Acknowledgments}

This work was supported by the National Science Foundation of China [grant number 41672295]; the National Key Research and Development Program of China [grant numbers 2019YFC1509904, 2018YFC1505404]; and the Geological Survey Program of China [grant number DD20190634]. The authors are immensely grateful to Sichuan Huadi Construction Engineering Co., Ltd. for providing the drilling data and geological maps of the Tizicao landslide.

\section{References}


1. Arne D, Worley B, Wilson C, Chen SF, Foster D, Luo ZL, Liu SG, Dirks P (1997) Differential exhumation in response to episodic thrusting along the eastern margin of the Tibetan Plateau. Tectonophysics 280(3-4):239-256. https://doi.org/10.1016/S0040-1951(97)00040-1

2. Broili L (1967) New knowledges on the geomorphology of the Vaiont slide slip surfaces.

Felsmechanik Ingenieurgeologie 5(1):38-88

3. Cała M (2007) Convex and concave slope stability analyses with numerical methods. Arch Min Sci 52:75-89. https://doi.org/10.1002/bimj.200610324

4. Chen H, Qin S, Xue L, Yang B, Zhang K (2018) A physical model predicting instability of rock slopes with locked segments along a potential slip surface. Eng Geol 242:34-43.

https://doi.org/10.1016/j.enggeo.2018.05.012

5. Deng J, Hao Y, Yu Z, Xie H (2019) Analysis on the Formation Mechanism and Process of Baige Landslides Damming the Upper Reach of Jinsha River, China. Advanced Engineering Sciences 51(1):9-16. https://doi.org/10.15961/j.jsuese.201801438

6. Einstein H, Veneziano D, Baecher G, Oreilly K (1983) The effect of discontinuity persistence on rock slope stability. Int J Rock Mech Min Sci 20(5):227-236. https://doi.org/10.1016/01489062(83)90003-7

7. Feda J (1977) Stresses in a natural slope. Bull Eng Geol Env 16(1):201-202. https://doi.org/10.1007/BF02591482

8. Frayssines M, Hantz D (2006) Failure mechanisms and triggering factors in calcareous cliffs of the subalpine ranges (French alps). Eng Geol 86(4):256-270. https://doi.org/10.1016/j.enggeo.2006.05.009

9. Ferguson RI, Parsons DR, Lane SN (2003) Flow in meander bends with recirculation at the inner bank. Water Resour Res 39(11):1-13. https://doi.org/10.1029/2003WR001965

10. Ghirotti M, Martin S, Genovois R (2011) The Celentino deep-seated gravitational slope deformation (DSGSD): Structural and geomechanical analyses (Peio Valley, NE Italy). In: Jaboyedoff, M. (Ed.), Slope Tectonics. Geological Society London, London, Special Publications 351:235-252

11. Hoek E, Bray JW (1981) Rock slope engineering, Third edition. Institute of Mining and Metallurgy, London. ISBN: 9780429182198

12. Huang R (2012) Mechanisms of large-scale landslides in China. Bull Eng Geol Environ 71(1):161170. https://doi.org/10.1007/s10064-011-0403-6

13. Jaeger JC (1971) Friction of rocks and stability of rock slopes-11th Rankine Lecture. Geotechnique 21(2):97-134

14. Jennings JE (1970) A mathematical theory for the calculation of the stability of slopes in open cast mines. In: Planning Open Pit Mines, Proceedings, Johannesburg 87-102

15. Kang Y, Lu Z, Zhao C, Zhang Q, Kim JW, Niu YF (2019) Diagnosis of Xinmo (China) Landslide Based on Interferometric Synthetic Aperture Radar Observation and Modeling. Remote Sensing 11(16):1846. https://doi.org/10.3390/rs11161846 
16. Keshavarzi A, Ball J (2010) River Bed and Bank Stability Using Convex,Concave and Linear Bed Sills. International symposium on hydraulic physical modeling and field investigation, Nanning 396-400

17. Kirby E, Reiners PW, Krol MA, Whipple KX, Hodges KV, Farley KA, Tang WQ, Chen ZL (2002) Late Cenozoic evolution of the eastern margin of the Tibetan Plateau: Inferences from 40Ar/39Ar and (UTh)/He thermochronology. Tectonics 21(1):1-20. https://doi.org/10.1029/2000TC001246

18. Lin F, Wu LZ, Huang RQ, Zhang H (2018) Formation and characteristics of the Xiaoba landslide in Fuquan. Guizhou China Landslides 15(4):669-681. https://doi.org/10.1007/s10346-017-0897-5

19. Lulseged Ayalew $H$ Yamagishi (2004) Slope failures in the Blue Nile basin, as seen from landscape evolution perspective. Geomorphology 57(1-2):95-116. https://doi.org/10.1016/S0169555X(03)00085-0

20. Massey C, Pasqua F, Francois-Holden C, Kaiser A, Richards L, Wartman J, McSaveney M, Archibald G, Yetton M, Janků L (2016) Rock slope response to strong earthquake shaking. Landslides 14:1-20. https://doi.org/10.1007/s10346-016-0684-8

21. Mitchell S, Montgomery D, Greenberg H (2009) Erosional unloading, hillslope geometry, and the height of the Cascade Range, Washington State, USA. Earth Surf Proc Land 34:1108-1120. https://doi.org/10.1002/esp.1801

22. Pariseau WG, Puri S, Schmelter C (2008) A new model for effects of impersistent joint sets on rock slope stability[J]. Int J Rock Mech Min Sci 45(2):122-131. https://doi.org/10.1016/j.jirmms.2007.05.001

23. Sichuan Huadi Construction Engineering Co., Ltd (2018) Report of emergency survey of Tizicao landslide in Shuangma village, Shidaguan Town, Maoxian county, China. (in Chinese)

24. Schnauder I, Sukhodolov AN (2012) Flow in a tightly curving meander bend: effects of seasonal changes in aquatic macrophyte cover. Earth Surf Proc Land 37(11):1142-1157. https://doi.org/10.1002/esp.3234

25. Sun YZ, Huang RQ (2012) Research on quantification index of rock mass in riverside unloading zone classification. Chin J Rock Mechan Eng 31(A2):3942-3949. (in Chinese)

26. Wang GL, Zhang L, Huang ZW, Liu BL, Qiu PY (2019b) Analysis of the seismic effect of slopes with different shapes under dynamic loads. Geotech Geol Eng 37:1779-1791. https://doi.org/10.1007/s10706-018-0722-5

27. Wang HH, Nie DL, Tuo XG, Zhong YS (2020) Research on crack monitoring at the trailing edge of landslides based on image processing. Landslides 17(4):985-1007. https://doi.org/10.1007/s10346-019-01335-z

28. Wang WP, Yin YP, Yang LW, Zhang N, Wei YJ (2019a) Investigation and dynamic analysis of the catastrophic rockslide avalanche at Xinmo, Maoxian, after the Wenchuan Ms 8.0 earthquake. Bull Eng Geol Env 79(4):495-512. https://doi.org/10.1007/s10064-019-01557-4

29. Xie ZY, Yang CL, Dong CY, Dai X, Zhang L, Guo JY, Guo ZQ, Li ZS (2020) Geochemical characteristics and genesis of the Middle Devonian and the Middle Permian natural gas in the Sichuan Basin, China. Journal of Natural Gas Geoscience 5(4):185-198. https://doi.org/10.1016/j.jnggs.2020.06.002 
30. Xu Q, Fan XM, Huang RQ, Yin YP, Hou SS, Dong XJ, Tang MG (2010) A catastrophic rockslide-debris flow in Wulong, Chongqing, China in 2009: background, characterization, and causes. Landslides 7(1):75-87. https://doi.org/10.1007/s10346-009-0179-y

31. Xu WJ, Jie YX, Li QB, Wang XB, Yu YZ (2014) Genesis, mechanism, and stability of the Dongmiaojia landslide, yellow river, China. International Journal of Rock Mechanics Mining Sciences 67(2):57-68. https://doi.org/10.1016/j.jirmms.2014.01.010

32. Yasuda Y, Tsuchiya S, Mizuyama T, Matsumura K, Ochiai H, Takahashi M, Tang W (2016)

Topographic effects of the seismic slope displacement and ground acceleration by earthquake using a dynamic response analysis. Sabo Gakkaishi 59(8):3-11.

https://doi.org/10.1097/01.alc.0000175073.94575.86

33. Yin YP, Sun P, Zhang M, Li B (2011) Mechanism on apparent dip sliding of oblique inclined bedding rockslide at Jiweishan, Chongqing, China. Landslides 8(1):49-65. https://doi.org/10.1007/s10346010-0237-5

34. Zhang YQ, Yang N, Meng H (2005) Deep-incised valleys along the Minjiang river upstream and their responses to the uplift of the West Sichuan Plateau, China. Journal of Chengdu University of Technology: Sci Technol Ed 4:331-339. (in Chinese)

\section{Figures}




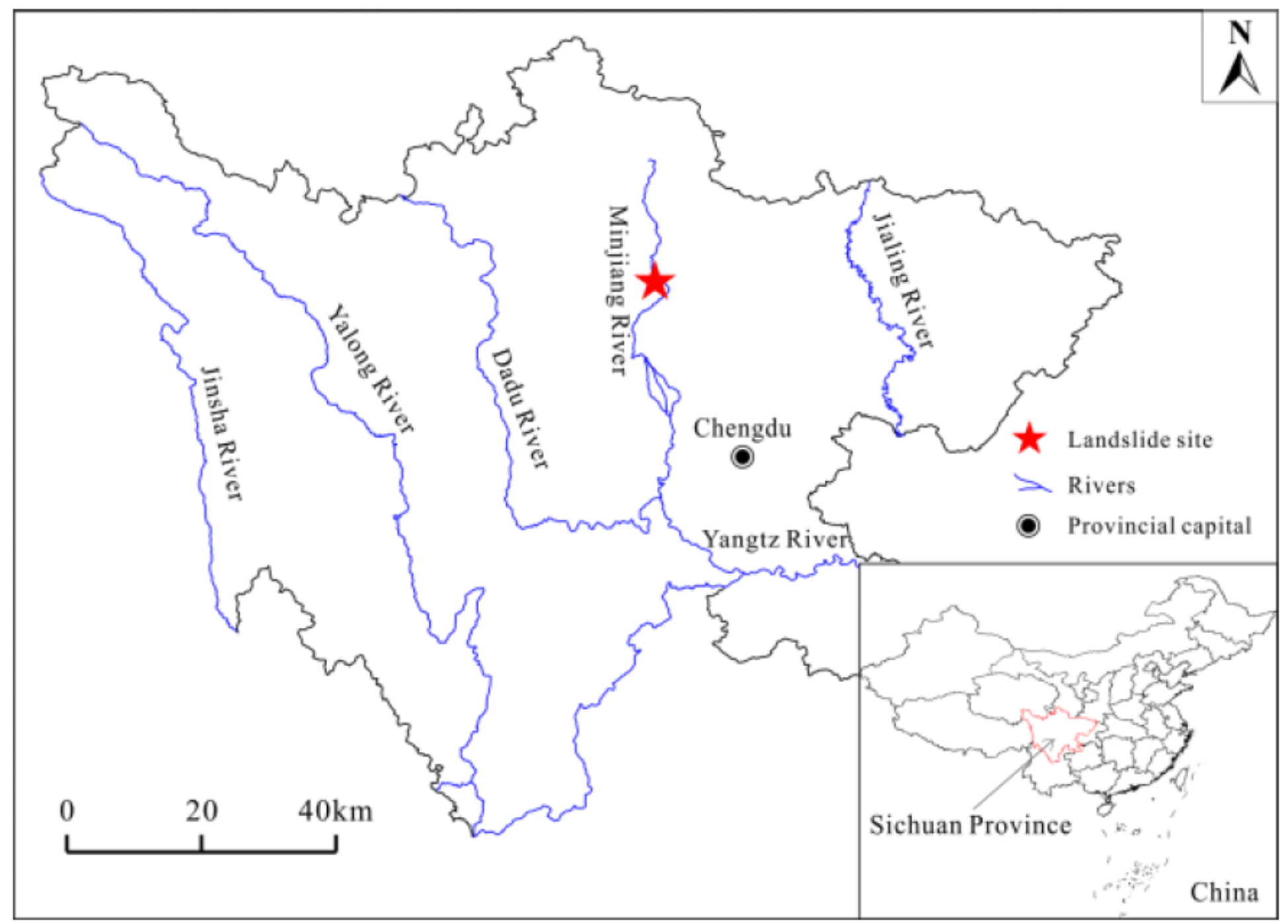

Figure 1

Location of Tizicao landslide in the Southwest of China 

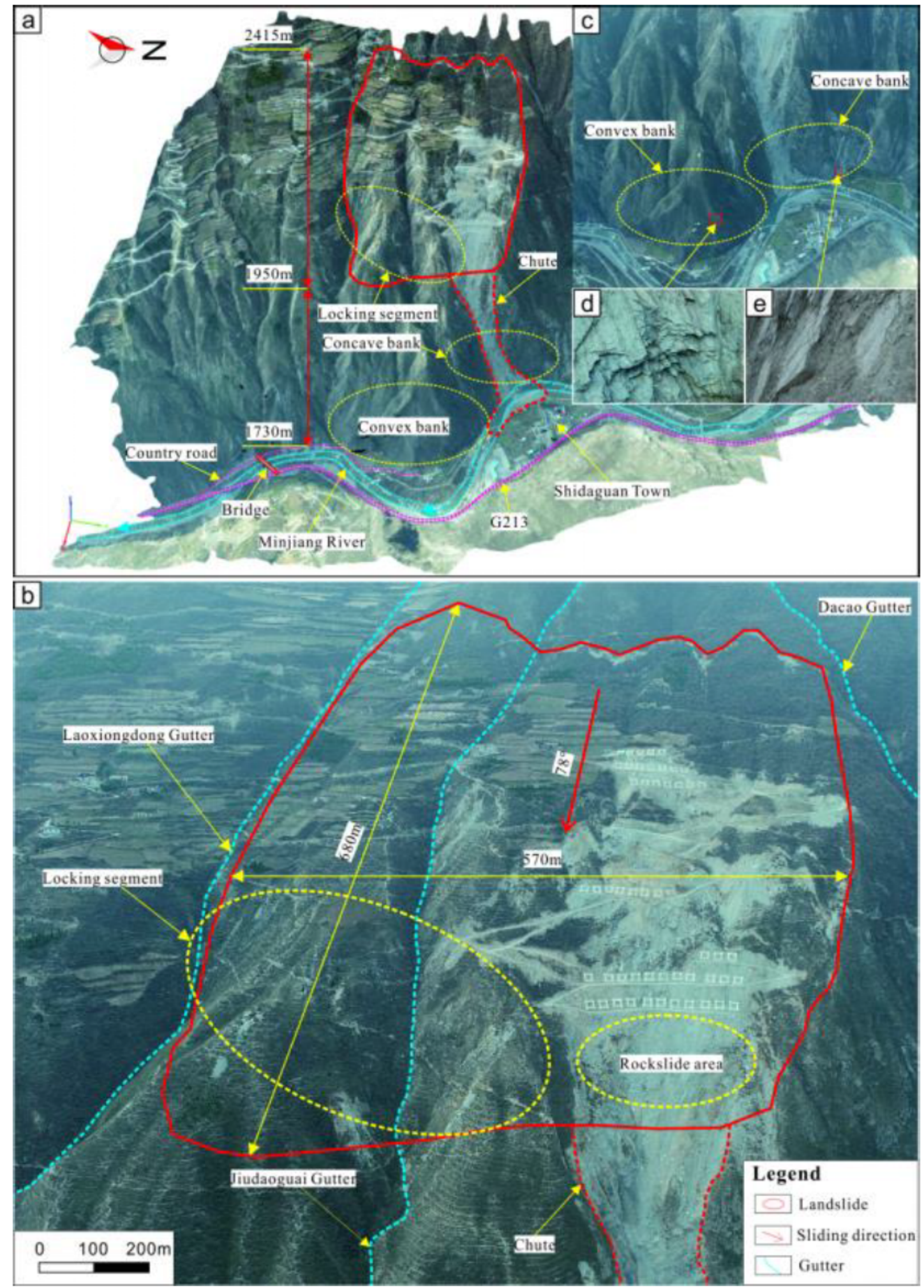

Figure 2

Overall perspective of the Tizicao landslide site area a An orthoimage of the landslide site area, b Oblique view of the landslide using drones, c Convex and concave bank parts below the landslide, $d$ Relatively intact phyllite in the convex bank part, e Broken phyllite in the concave bank part 


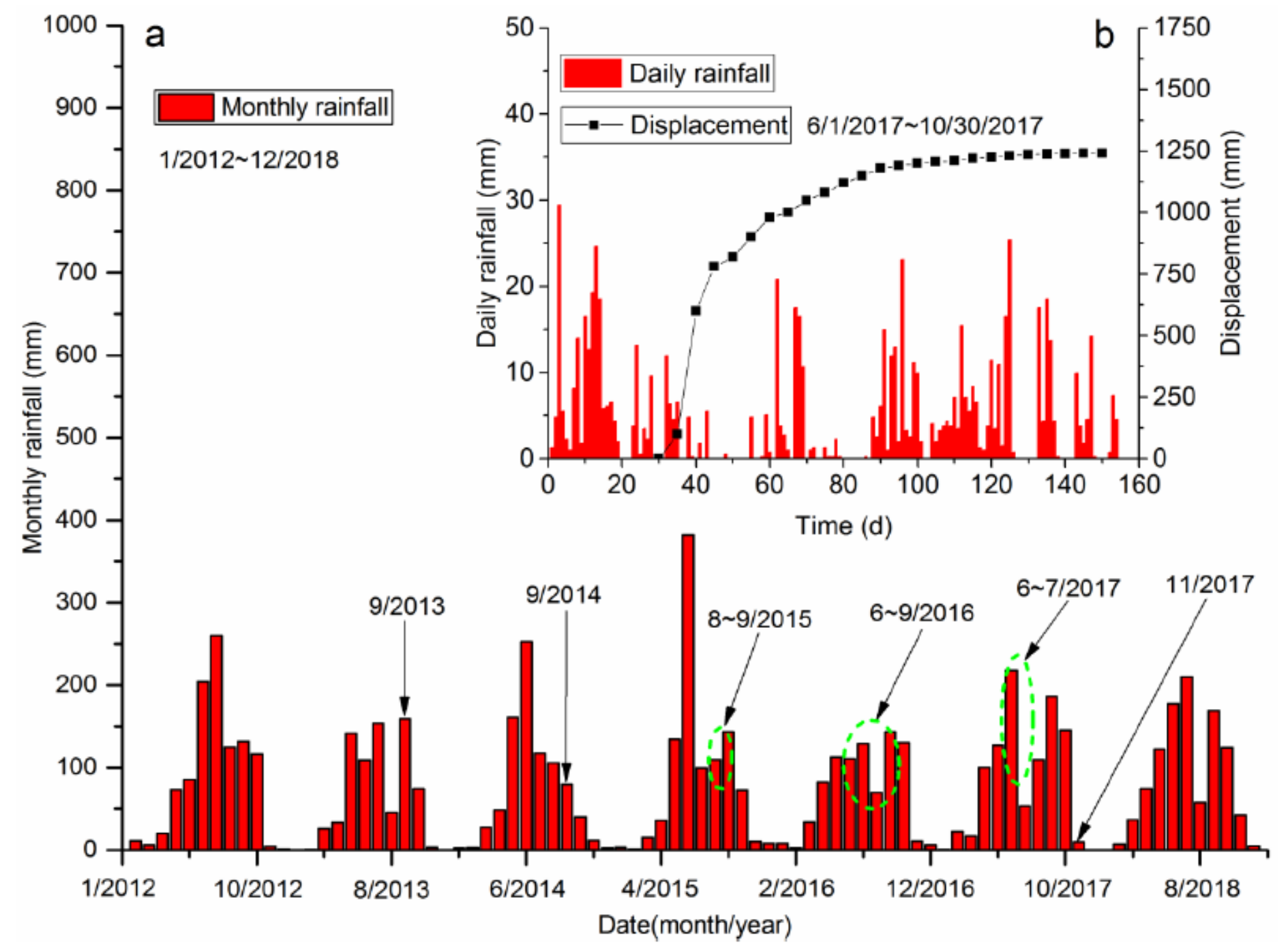

Figure 3

Rainfall statistics and one typical surface displacement monitored in the Tizicao landslide a Monthly rainfall from $1 / 2012$ to $12 / 2018$, with deformation dates of the landslide being indicated, b Daily rainfall and one typical surface displacement monitored from 6/1/2017 to 10/30/2017 


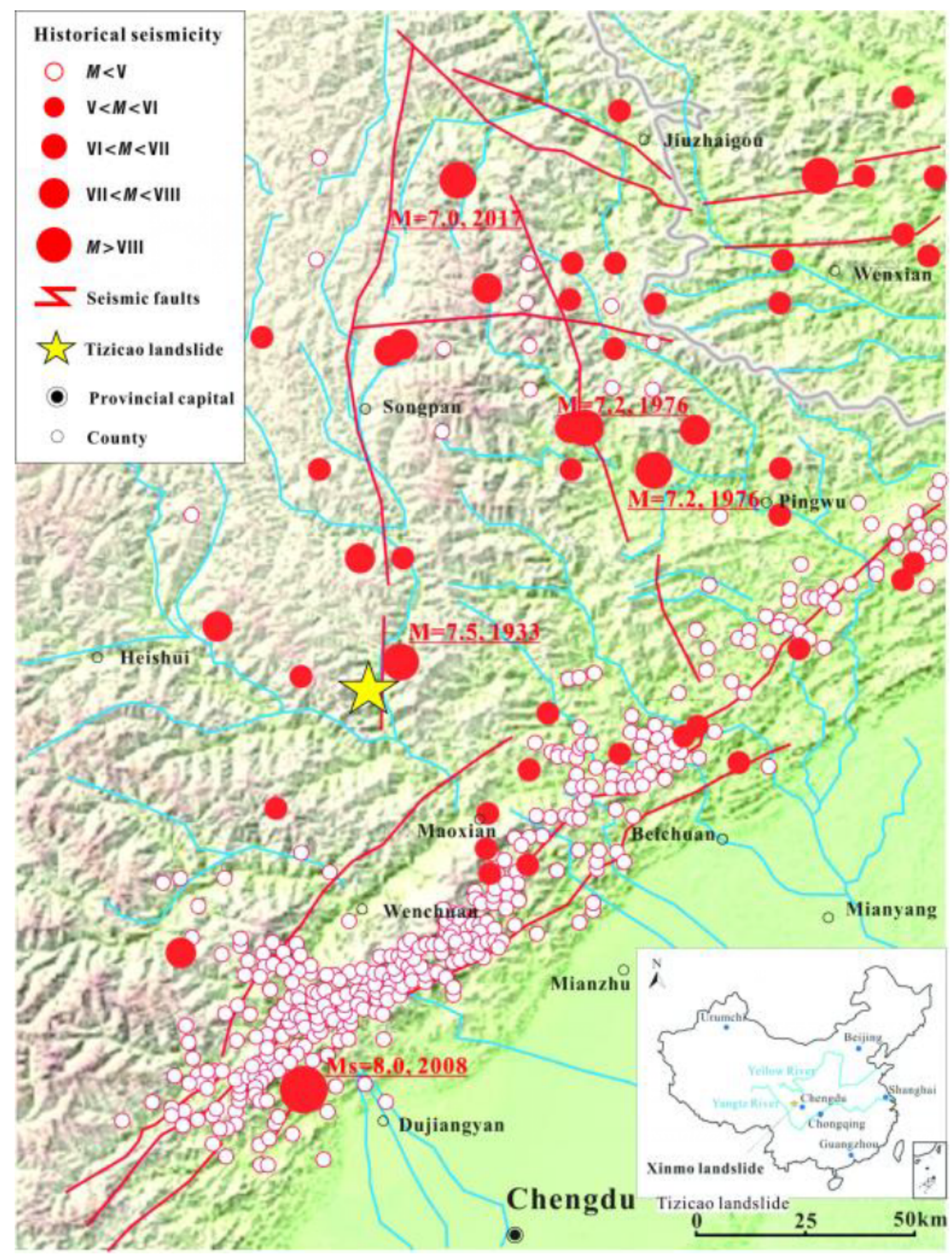

Figure 4

Locations of the historical earthquakes in the last 100 years (modified after Wang et al. 2019a) 

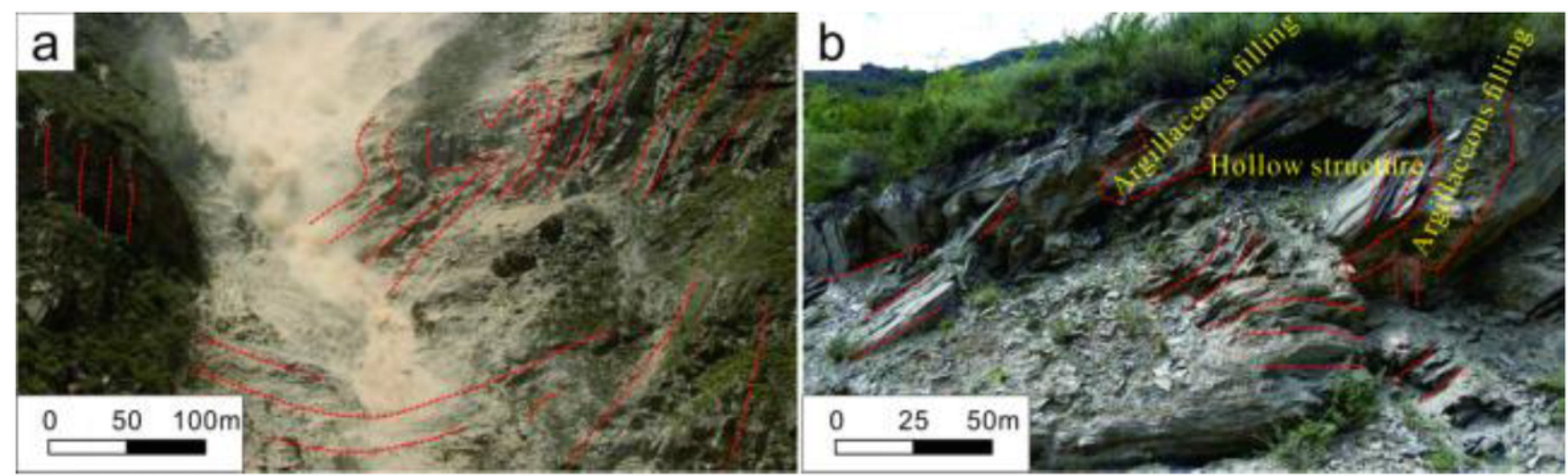

\section{Figure 5}

Small-scale tectonic movement in the front of the slope a Small-scale corrugations developing near the front chute in Tizicao landslide, b Fractured rock masses, secondary folds, hollow structures, and argillaceous fillings at the slope foot. The red dotted line represents the strata boundary 


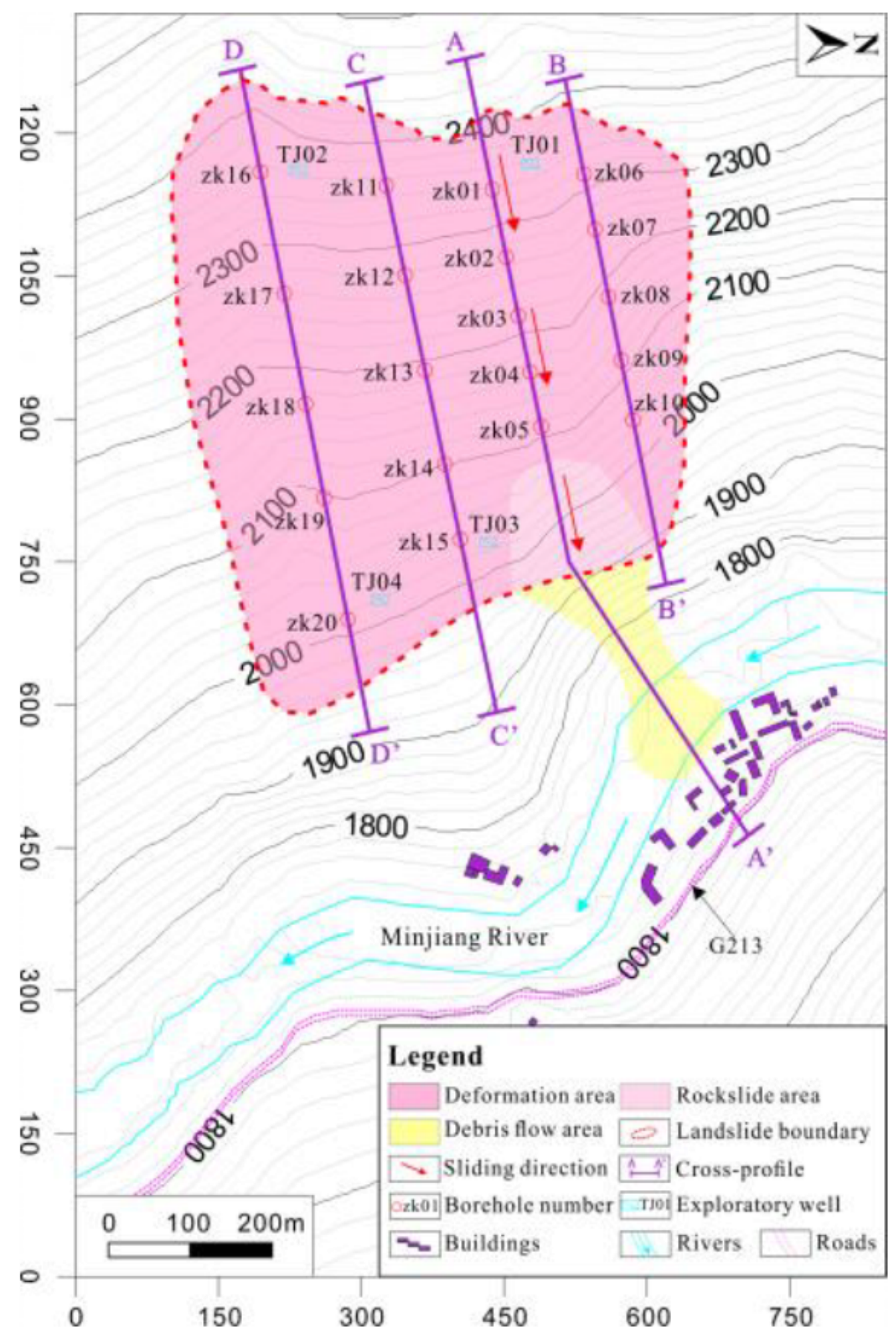

\section{Figure 6}

Topographic plan of the Tizicao landslide. Four engineering-geological profiles were marked as A-A', B-B', $C-C^{\prime}$, and D-D', zk01-zk20 represent the numbers of the twenty boreholes; TJ01-TJ04 denote the numbers of the four exploratory wells 


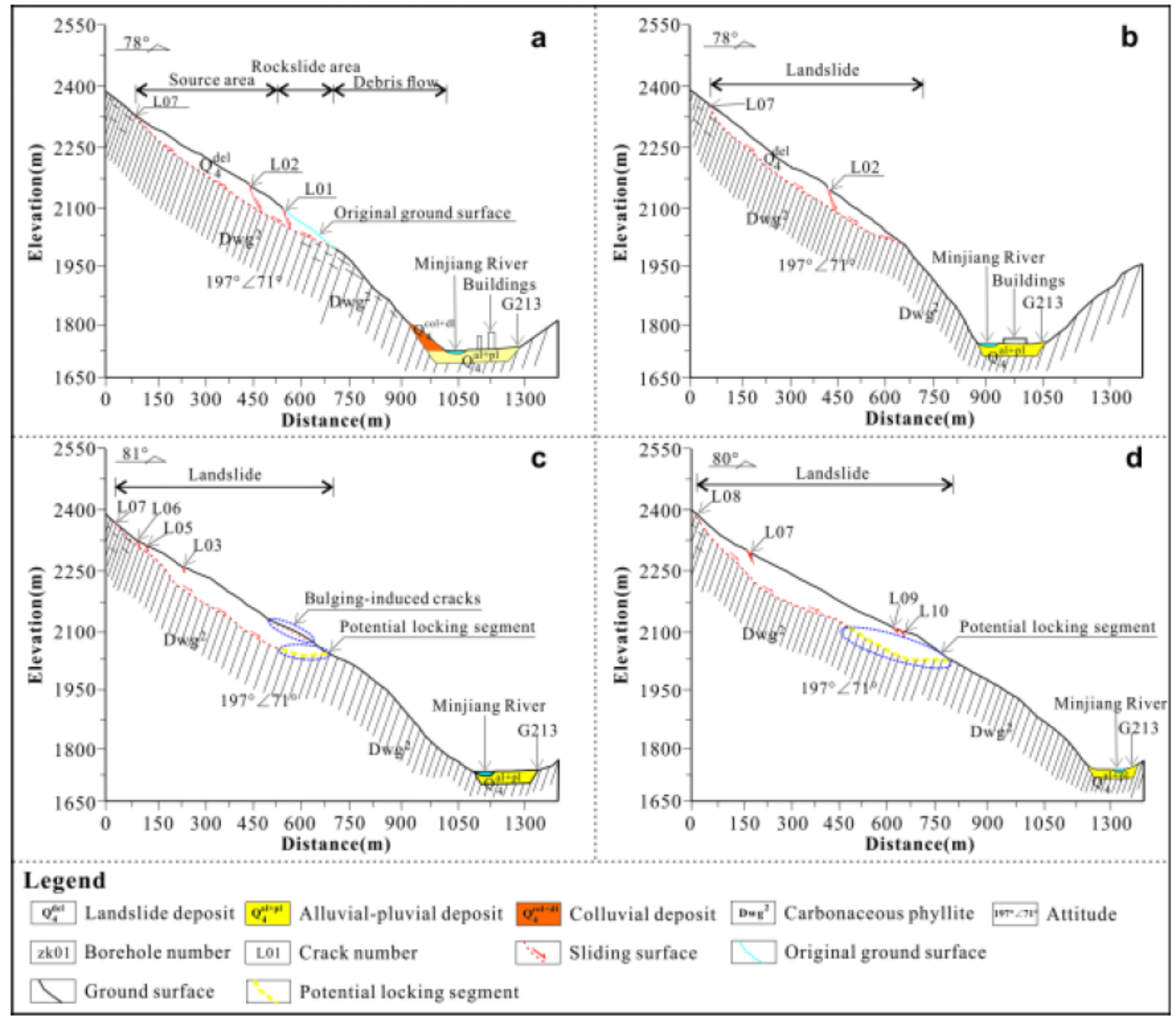

Figure 7

Engineering-geotechnical profiles of Tizicao landslide a Profile A-A', b Profile B-B', c Profile C-C', d Profile D-D' 


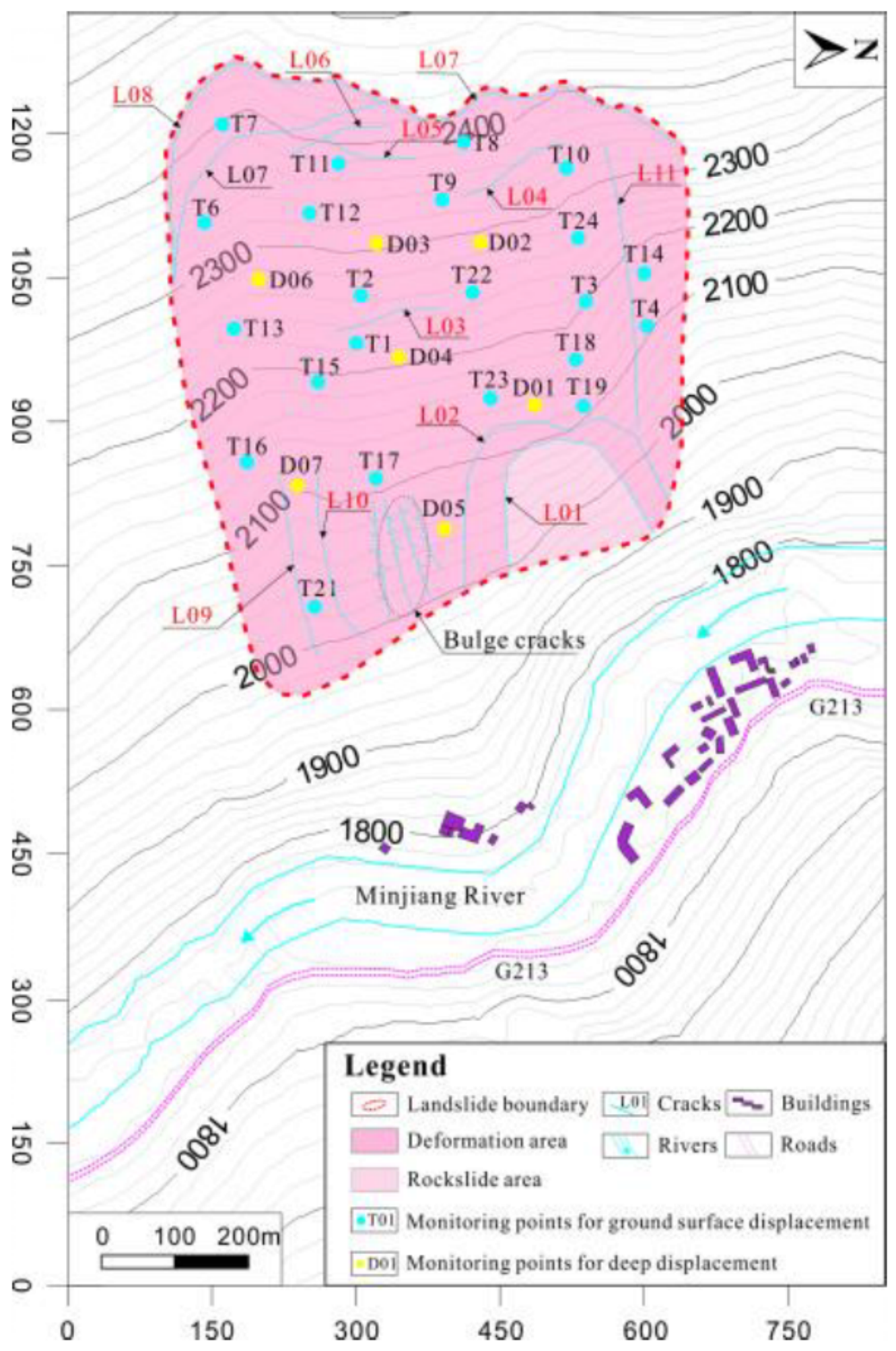

\section{Figure 8}

Plan showing the cracks development and monitoring points layout in Tizicao landslide. L01-L11 refer to the numbers of 11 cracks developing in the landslide; besides, there are great numbers of bulging-induced fissures in the middle part of the landslide front; T1-T24 represent 24 fixed non-prism monitoring points; D01-D07 represent seven boreholes used to monitor the deep displacement of the landslide 


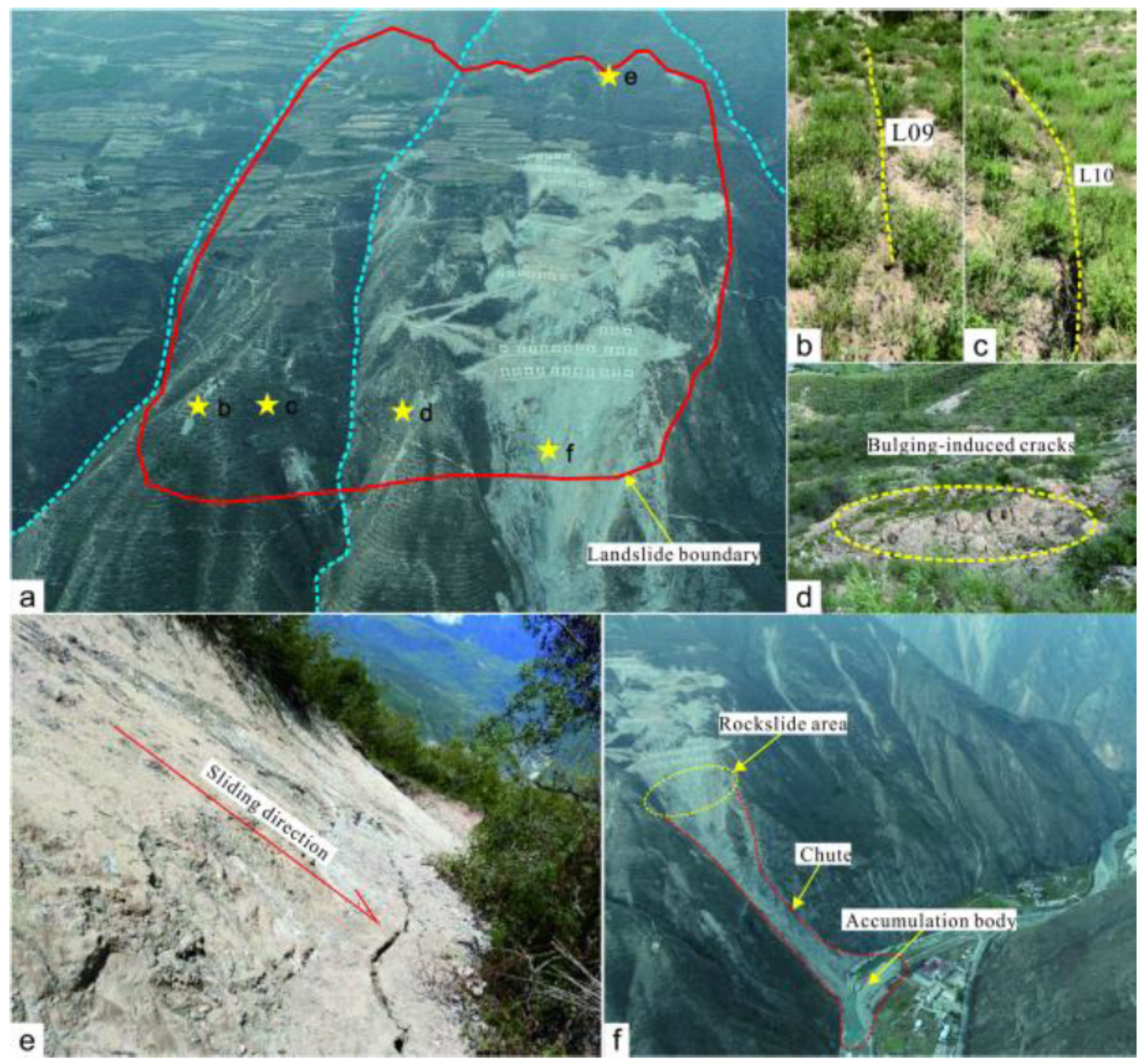

\section{Figure 9}

Photos showing the development of cracks and deformation in Tizicao landslide a A photo of crack locations; the yellow five-pointed stars represent the locations of the cracks, b Photo of the site of cracks L09. c Photo of the site of cracks L10, d A photo of bulging-induced cracks, e Rear wall of the landslide, $f$ Rockslide area, chute and accumulation body 


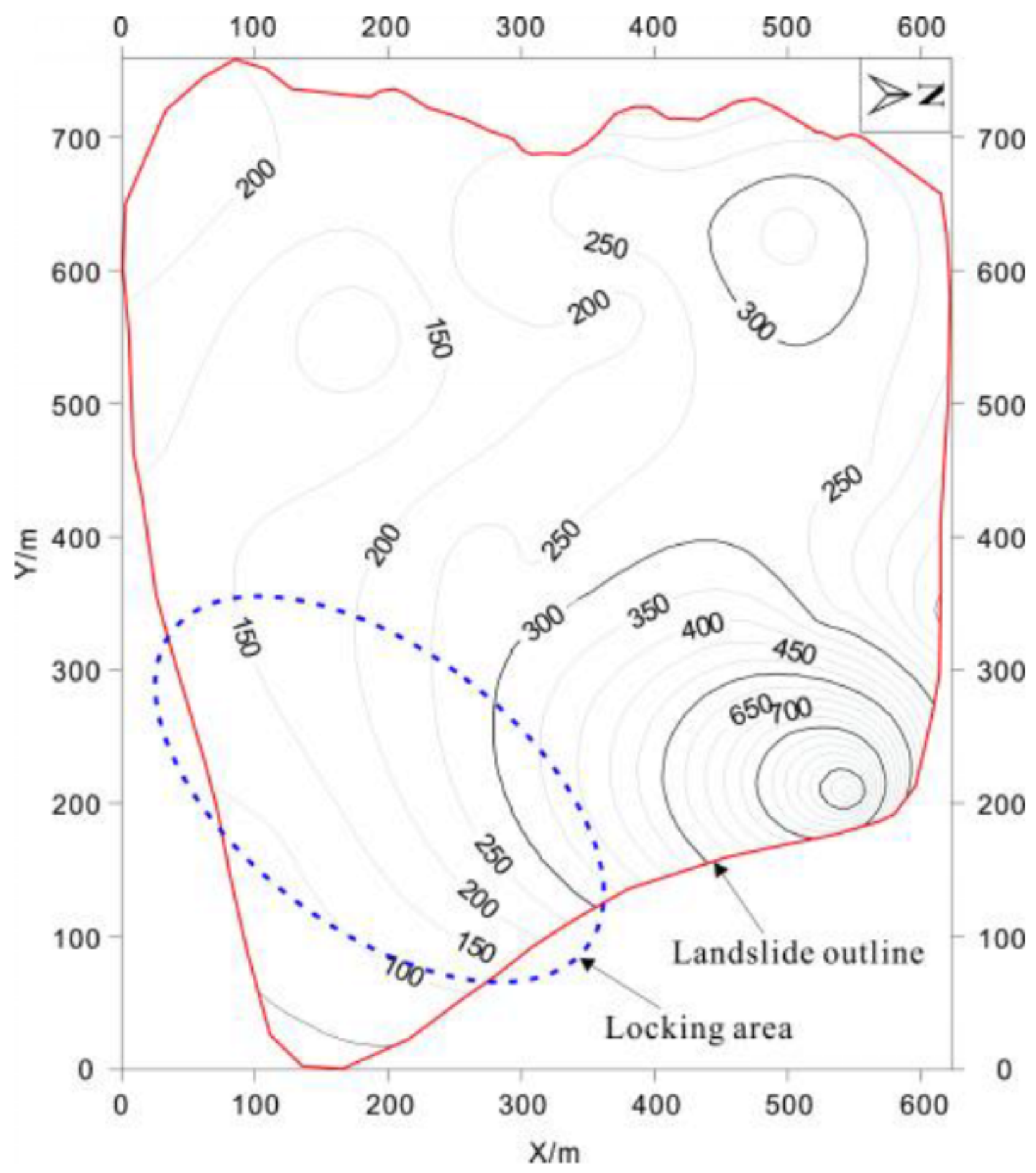

Figure 10

Isoline map of the surface displacement of Tizicao landslide from June 1, 2017, to October 2, 2017 (unit: $\mathrm{mm}$ ) 


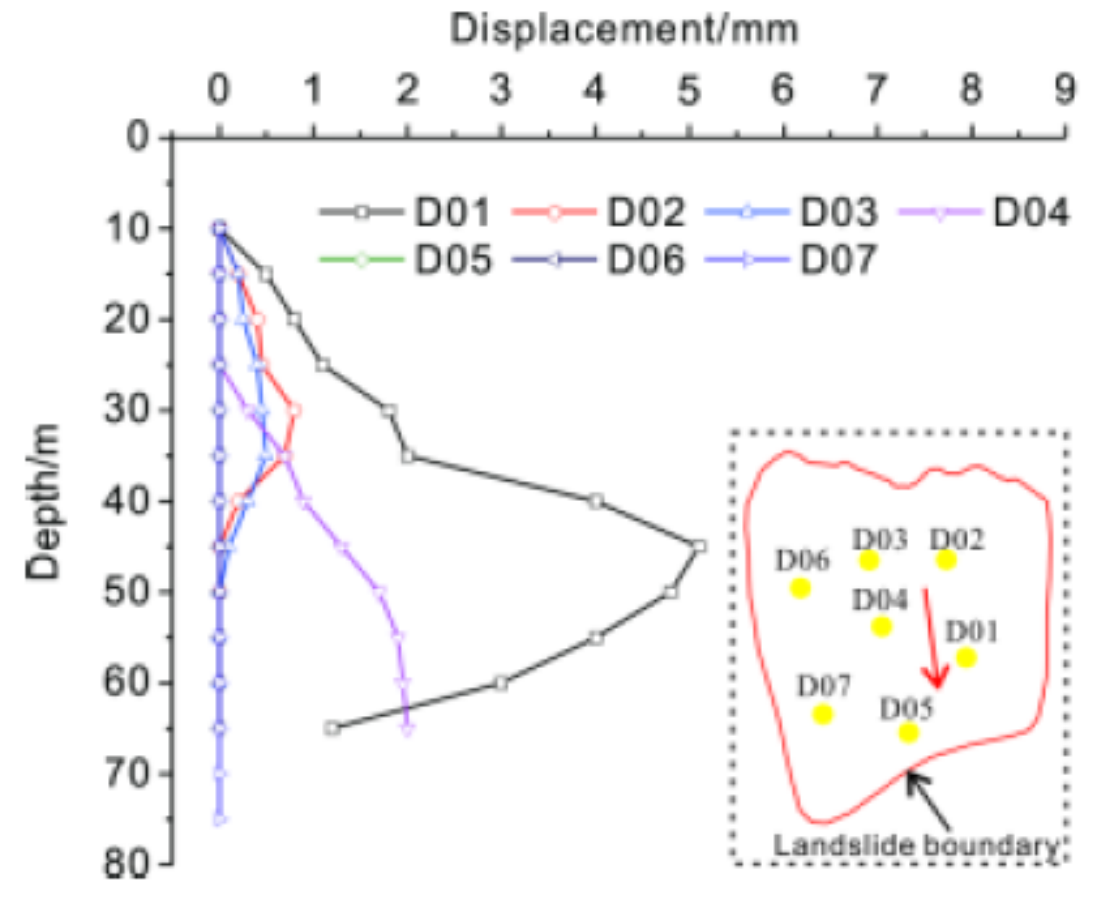

Figure 11

Curves of cumulative deep displacement of the Tizicao landslide from December 5, 2017, to February 6, 2018
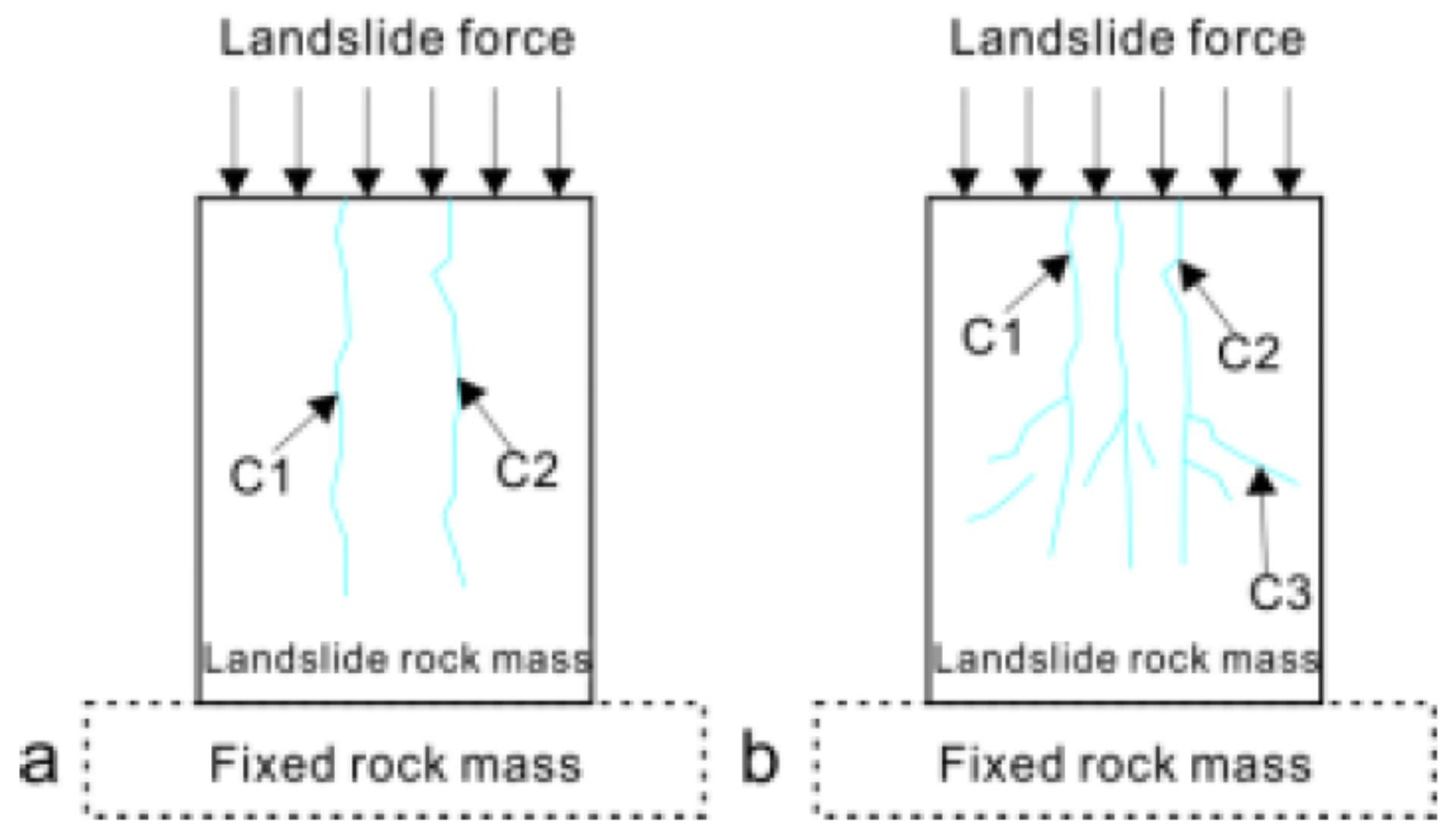

Figure 12 
Sketches showing the formation processes of compressive and bulging-induced cracks in landslides a Crack propagation in a relatively intact rock mass; $\mathrm{C} 1$ and $\mathrm{C} 2$ are the compressive cracks, b Crack propagation in a relatively fractured rock mass; $\mathrm{C} 3$ is the bulging-induced crack
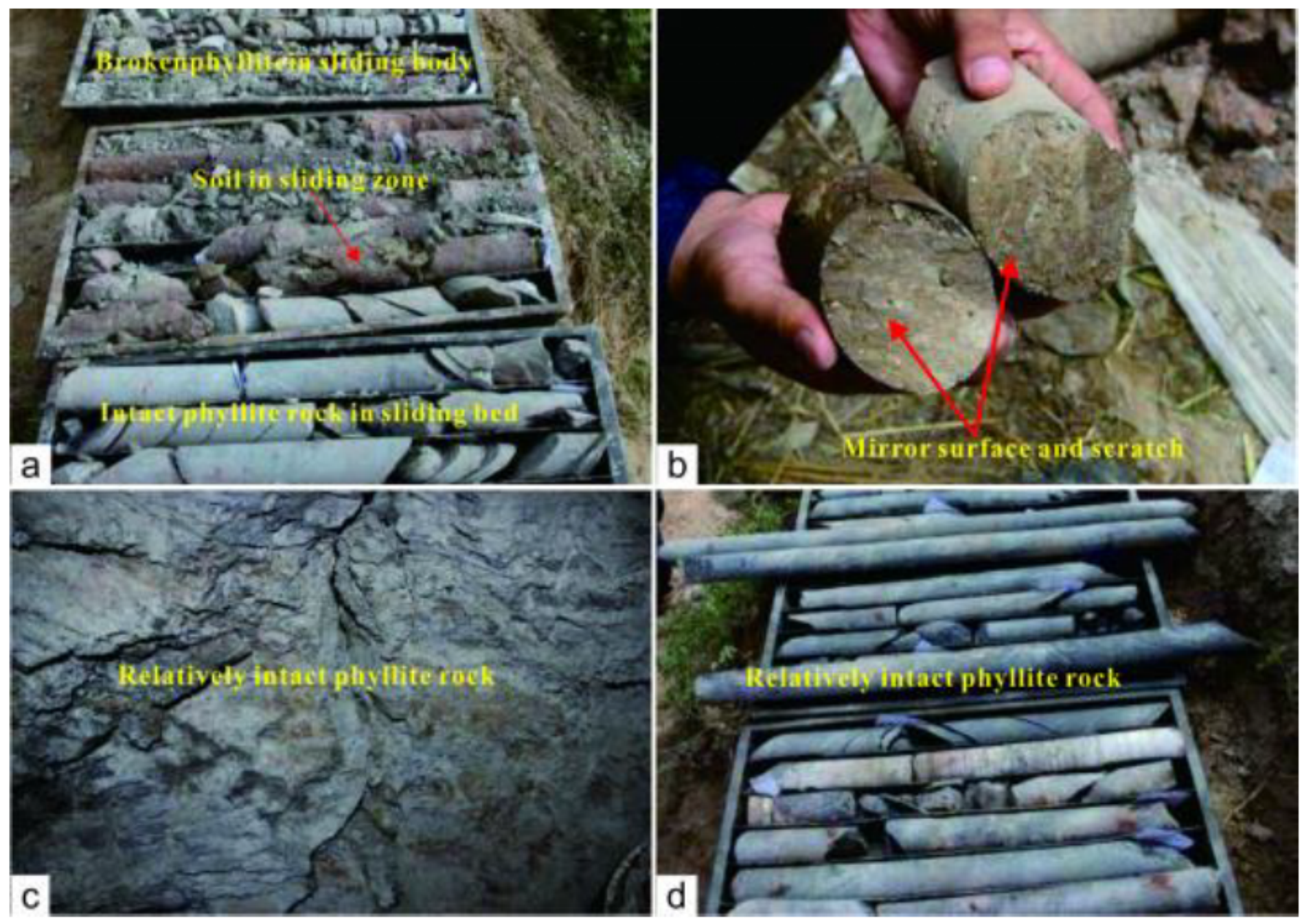

Figure 13

Photos of borehole cores and phyllite rock masses a Broken phyllite in sliding body, soil in sliding zone, and phyllite in sliding bed revealed by borehole zk08, b Mirror surface and scratch developing in the sliding zone soil discovered by borehole zk03, c Relatively intact phyllite revealed by exploratory well TJ04 at the depth of $6 \mathrm{~m}$, d Relatively intact phyllite revealed by borehole zk20 


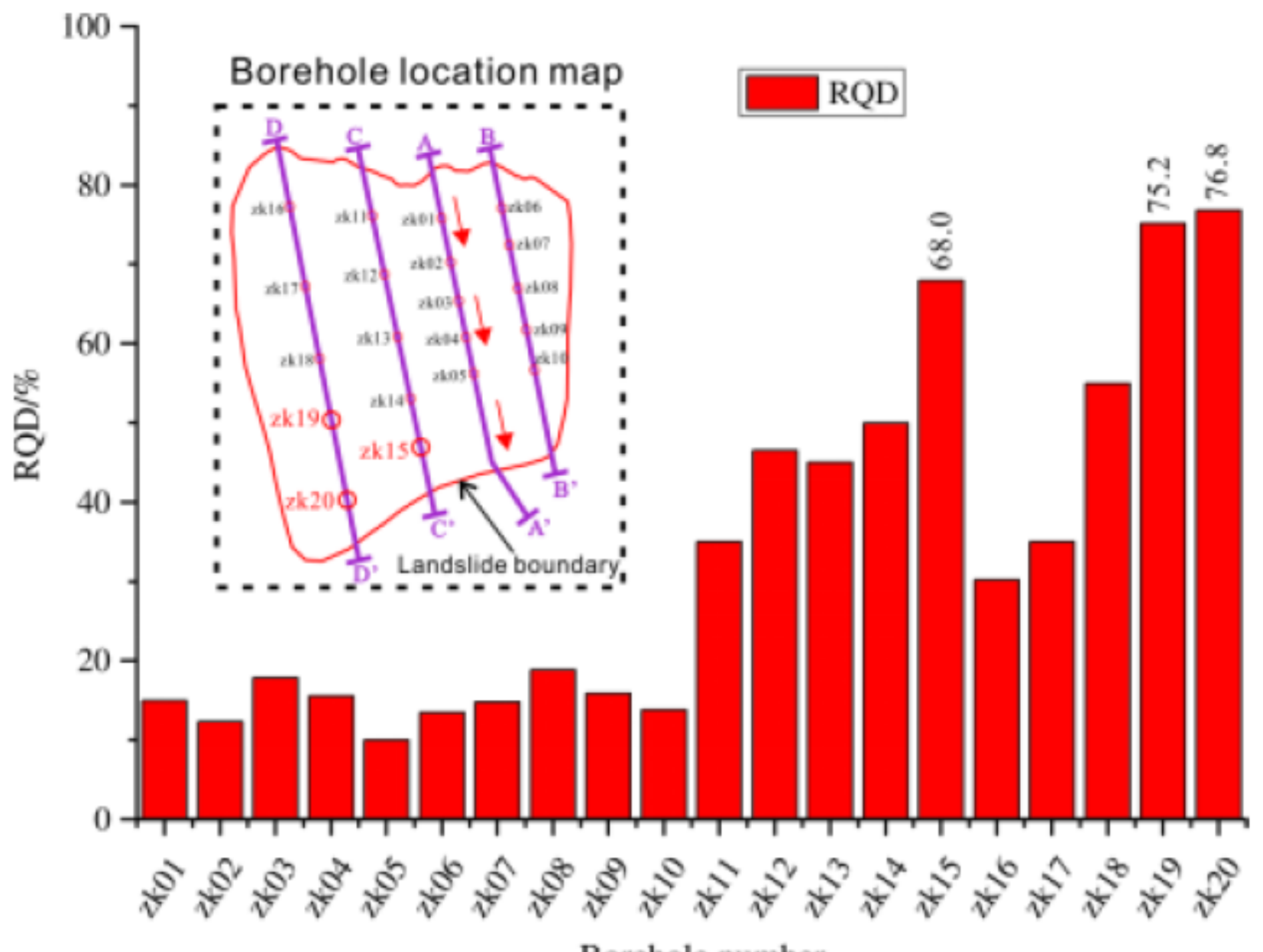

Borehole number

Figure 14

$R Q D$ values of borehole cores 